\title{
Consumo e digestibilidade aparente total dos nutrientes, produção e composição do leite de vacas alimentadas com dietas contendo diferentes fontes de proteína ${ }^{1}$
}

\author{
Douglas dos Santos Pina ${ }^{2}$, Sebastião de Campos Valadares Filho ${ }^{3}$, Rilene Ferreira Diniz \\ Valadares ${ }^{4}$, José Maurício de Souza Campos ${ }^{3}$, Edenio Detmann ${ }^{3}$, Marcos Inácio Marcondes ${ }^{5}$, \\ André Soares de Oliveira ${ }^{2}$, Rafael Monteiro Araújo Teixeira ${ }^{2}$
}

\author{
1 Parte da dissertação de Mestrado, parcialmente financiada pelo CNPq e pela FAPEMIG. \\ 2 Doutorando em Zootecnia - UFV. Bolsista do CNPq. \\ ${ }^{3}$ Departamento de Zootecnia - UFV. Pesquisador do CNPq. \\ ${ }^{4}$ Departamento de Veterinária - UFV. Pesquisadora do CNPq. \\ 5 Graduação em Zootecnia - UFV. Bolsista do PIBIC - CNPq.
}

\begin{abstract}
RESUMO - Foram utilizadas 12 vacas da raça Holandesa distribuídas em três quadrados latinos 4 x 4 , organizados de acordo com os dias em lactação, com o objetivo de avaliar o efeito de diferentes fontes protéicas na dieta sobre o consumo e a digestibilidade dos nutrientes e a produção e composição do leite. Utilizou-se silagem de milho como volumoso, na proporção de $60 \%$ da MS total. Os concentrados foram constituídos de diferentes fontes protéicas (FS - farelo de soja; FA38 - farelo de algodão 38\% PB; FA28 - farelo de algodão 28\% PB e FSU - farelo de soja + 5\% de uréia/sulfato de amônia na MS do concentrado). Os consumos de MS e MO não diferiram entre as dietas, mas os de NDT foram maiores na dieta controle. Os coeficientes de digestibilidade (CD) da MS e MO foram menores para as dietas FA38, FA28 e FSU. A produção de leite (PL), corrigida ou não para 3,5\% (PLC) de gordura, o teor e a produção de gordura do leite não foram influenciados pelas diferentes fontes protéicas, mas a eficiência de utilização da MS e do nitrogênio dietético para a PL e o teor e a produção de proteína do leite foram inferiores para as dietas contendo farelo de algodão em relação àquela com FS. Vacas com produção média de $25 \mathrm{~kg}$ de leite/dia podem ser alimentadas com dietas contendo 5\% de uréia/sulfato de amônia na MS do concentrado ou farelo de algodão $(38 \% \mathrm{~PB})$ quando utilizada silagem de milho como volumoso na proporção de $60 \%$ da MS total das dietas.
\end{abstract}

Palavras-chave: farelo de algodão, farelo de soja, leite, uréia

\section{Intake, apparent total tract digestibility of nutrients, and milk yield and composition of dairy cows fed diets supplemented with different protein sources}

\begin{abstract}
Twelve Holstein lactating dairy cows were blocked by days in milk and randomly assigned to three replicated $4 \times 4$ Latin square to evaluate the effect of different protein sources on intake, nutrient digestibility, and milk production and composition. A basal corn silage diet ( $60 \%$ of the total dry matter) was fed plus one of the following proteins sources (dry matter basis): soybean meal (SBM), cottonseed meal with $38 \%$ of crude protein (CSM38), cottonseed meal with $28 \%$ of crude protein (CSM28), or soybean meal plus $5 \%$ of urea/ammonium sulfate (SBMU). Intakes of dry matter (DMI) and organic matter (OMI) did not differ among diets but intake of total digestible nutrients (TDN) was greatest on the SBM diet. The digestibility coefficients (DC) of DM and OM were lower on CSM38, CSM28, and SBMU diets when compared to the SBM diet. Milk yield (MY), 3.5\% fat corrected milk, and milk fat content and yield all were not affected by feeding different protein sources to lactating dairy cows. However, feed and nitrogen efficiencies and milk protein content and yield were lower in the CSM diets than on diets supplemented with SBM. It can be concluded that milk yield was maintained when cows were fed SBMU or CSM38 in diets with forage (corn silage) to concentrate ratio of 60:40.
\end{abstract}

Key Words: cottonseed meal, milk, soybean meal, urea

\section{Introdução}

A produtividade de ruminantes depende de sua habilidade para consumir e obter energia dos alimentos disponíveis (Allen, 1996). O conhecimento da ingestão de alimen- tos, por ser o principal fator a afetar o desempenho e a eficiência produtiva do animal, é necessário para a formulação de dietas, a predição do desempenho animal e o planejamento e controle do sistema de produção. Segundo o NRC (2001), estimativas precisas da ingestão de MS são 
necessárias para evitar sub ou superalimentação e aumentar a eficiência alimentar, promovendo o uso eficiente de nutrientes.

Características físicas e químicas dos ingredientes dietéticos e suas interações - conteúdo de fibra, facilidade de hidrólise do amido e da fibra, fragilidade e tamanho de partículas, produtos de fermentação das silagens, quantidade e degradação ruminal da proteína dietética - podem ter grande efeito na IMS de vacas lactantes (Allen, 2000).

Após o conhecimento da composição química, a estimativa dos valores de digestibilidade é reconhecidamente essencial para determinar o valor nutritivo dos alimentos (Valadares Filho et al., 2000). Segundo Pereira et al. (2005 a,b), a digestibilidade dos nutrientes é um dos componentes básicos na determinação da energia dos alimentos para produção de leite, ou seja, energia líquida de lactação $\left(\mathrm{EL}_{\mathrm{L}}\right)$, energia metabolizável (EM), energia digestível (ED) ou NDT. Entretanto, existe uma complexa relação entre proteína dietética e energia e a quantidade de proteína utilizada pelo animal (Broderick, 2003).

O suprimento de proteína em quantidade e qualidade, observando suas relações com os demais ingredientes dietéticos, é muito importante, pois a proteína é o segundo nutriente limitante em dietas para ruminantes, de modo que as fontes protéicas podem ser consideradas o ingrediente mais oneroso na formulação de dietas para vacas lactantes, em virtude de seu grande requerimento e do elevado custo de fontes tradicionais, como o farelo de soja.

Em sistemas intensivos de produção de leite, nos quais são explorados animais de elevado potencial produtivo e, conseqüentemente, com elevados níveis de requerimento de nutrientes, o concentrado tem maior participação no custo de produção de leite (Ferreira, 2002).

A substituição do farelo soja por fontes protéicas alternativas sem o comprometimento do desempenho dos animais pode ser uma alternativa viável para reduzir os custos com alimentação do rebanho leiteiro. Por isso, cresce o interesse por parte dos pesquisadores quanto à utilização de uréia e farelo de algodão em dietas para vacas em lactação, de modo que o potencial de incorporação desses ingredientes em dietas para animais ruminantes requer cuidado, planejamento, avaliação e estudo. Rações formuladas com ingredientes alternativos devem ser eficientes, seguras e econômicas para permitir o mesmo desempenho produtivo de animais alimentados com dietas tradicionais.

Conduziu-se este trabalho com o objetivo de avaliar o efeito de diferentes fontes de proteína sobre a produção e composição do leite e o consumo e a digestibilidade dos nutrientes da dieta.

\section{Material e Métodos}

O experimento foi realizado na Unidade de Ensino, Pesquisa e Extensão em Gado de Leite (UEPE-GL) do Departamento de Zootecnia da Universidade Federal de Viçosa (UFV), Viçosa-MG. Foram utilizados 12 animais da raça Holandesa, com peso médio de $550 \mathrm{~kg}$ e produção de $25 \mathrm{~kg}$ de leite/dia, distribuídos em três quadrados latinos (QL) 4 x 4, organizados de acordo com os dias em lactação, que variaram em média de 60 a 120 dias. A proporção dos ingredientes na mistura de concentrados e a composição dos concentrados, da silagem de milho e das dietas experimentais são apresentadas nas Tabelas 1, 2 e 3, respectivamente.

Foram avaliadas quatro dietas constituídas de diferentes fontes protéicas: FS (farelo de soja); FA38 (farelo de algodão com $38 \%$ de PB); FA28 (farelo de algodão com $28 \%$ de PB) e FSU (farelo de soja com 5\% de uréia/sulfato de amônia). Utilizou-se silagem de milho como volumoso, na proporção de $60 \%$, com base na MS total da dieta. Os concentrados foram formulados de forma a serem isoprotéicos, com aproximadamente $26 \%$ de PB na matéria natural, e as dietas continham $15,5 \%$ de $\mathrm{PB}$ na MS, conforme proposto por Pereira et al. (2005 b). À exceção da dieta FSU, todas as demais foram adicionadas de 1,5\% de uréia/sulfato de amônia, com base na MS total dos concentrados. A dieta FA28 foi constituída da mesma proporção de farelo de algodão da dieta FA38 e, conseqüentemente, necessitou da adição de farelo de soja.

Tabela 1 - Proporção dos ingredientes nos concentrados, com base na MS

Table 1 - Ingredient composition of the concentrates, dry matter basis

\begin{tabular}{|c|c|c|c|c|}
\hline \multirow[t]{2}{*}{$\begin{array}{l}\text { Ingrediente } \\
\text { Ingredient }\end{array}$} & \multicolumn{4}{|c|}{$\begin{array}{l}\text { Concentrado } \\
\text { Concentrate }\end{array}$} \\
\hline & $\begin{array}{c}\text { FS } \\
S B M\end{array}$ & $\begin{array}{l}\text { FA38 } \\
\text { CSM } 38\end{array}$ & $\begin{array}{l}\text { FA28 } \\
\text { CSM } 28\end{array}$ & $\begin{array}{c}\text { FSU } \\
\text { SBMU }\end{array}$ \\
\hline $\begin{array}{l}\text { Fubá de milho } \\
\text { Ground corn }\end{array}$ & 43,67 & 29,81 & 15,42 & 62,01 \\
\hline $\begin{array}{l}\text { Farelo de soja } \\
\text { Soybean meal }\end{array}$ & 41,61 & - & 14,39 & 19,77 \\
\hline $\begin{array}{l}\text { Farelo de trigo } \\
\text { Wheat meal }\end{array}$ & 10,00 & 10,00 & 10,00 & 10,00 \\
\hline $\begin{array}{l}\text { Farelo de algodão } 38 \\
\text { Cottonseed meal } 38\end{array}$ & - & 55,47 & - & - \\
\hline $\begin{array}{l}\text { Farelo algodão } 28 \\
\text { Cottonseed meal } 28\end{array}$ & - & - & 55,47 & - \\
\hline $\begin{array}{l}\text { Uréia/SA } \\
\text { UreaAS }\end{array}$ & 1,50 & 1,50 & 1,50 & 5,00 \\
\hline $\begin{array}{l}\text { Mistura mineral } \\
\text { Mineral mix }\end{array}$ & 3,22 & 3,22 & 3,22 & 3,22 \\
\hline
\end{tabular}

$\mathrm{FS}=$ farelo de soja; FA38 = farelo de algodão com $38 \%$ de PB; FA28 = farelo de algodão com $28 \%$ de PB e FSU = FS + uréia (SBM = soybean meal; $C S M 38=$ cottonseed meal with $38 \%$ CP; CSM28 = cottonseed meal with $28 \% C P$ and SBMU = SBM plus urea). 
Tabela 2 - Teores médios de MS, MO, PB, proteína degradada no rúmen (PDR), proteína não-degradada no rúmen (PNDR), compostos nitrogenados não-protéicos (NNP), NIDA, EE, FDN, FDNcp, CNF, LIG e NDT obtidos nos concentrados e na silagem de milho

Table 2 - $\quad$ Average contents of DM, OM, CP, RDP, RUP, NPN, ADIN, EE, NDF, NDFap, NFC, lignin, and TDN of concentrates and corn silage

\begin{tabular}{|c|c|c|c|c|c|}
\hline \multirow[t]{2}{*}{ Item } & \multicolumn{4}{|c|}{$\begin{array}{l}\text { Concentrado } \\
\text { Concentrate }\end{array}$} & \multirow[t]{2}{*}{$\begin{array}{c}\text { Silagem } \\
\text { Silage }\end{array}$} \\
\hline & $\begin{array}{c}\mathrm{FS} \\
S B M\end{array}$ & $\begin{array}{l}\text { FA38 } \\
\text { CSM38 }\end{array}$ & $\begin{array}{l}\text { FA28 } \\
\text { CSM } 28\end{array}$ & $\begin{array}{c}\text { FSU } \\
S B M U\end{array}$ & \\
\hline $\mathrm{MS}(D M, \%)$ & 87,94 & 88,66 & 89,02 & 88,29 & 29,76 \\
\hline $\operatorname{MO}(O M)^{1}$ & 92,79 & 92,00 & 92,15 & 93,94 & 95,19 \\
\hline $\mathrm{PB}(C P)^{1}$ & 28,89 & 30,53 & 28,73 & 28,67 & 5,26 \\
\hline $\operatorname{PDR}(R D P)^{1}$ & 18,34 & 19,55 & 20,32 & 21,95 & 4,45 \\
\hline $\operatorname{PNDR}(R U P)^{1}$ & 10,55 & 10,99 & 8,41 & 6,71 & 0,81 \\
\hline $\mathrm{NNP}(N P N)^{2}$ & 21,53 & 22,60 & 24,10 & 48,85 & 44,51 \\
\hline NIDA $(A D I N)^{2}$ & 0,74 & 0,44 & 0,83 & 0,69 & 2,28 \\
\hline $\mathrm{EE}^{1}$ & 2,42 & 2,91 & 1,54 & 2,89 & 2,15 \\
\hline FDN $(N D F)^{1}$ & 16,54 & 29,97 & 38,74 & 16,16 & 62,34 \\
\hline FDNcp $(\text { NDFap })^{1}$ & 10,89 & 27,68 & 33,31 & 11,60 & 58,54 \\
\hline $\mathrm{CNF}(N F C)^{1}$ & 47,19 & 30,84 & 25,40 & 53,72 & 25,43 \\
\hline $\mathrm{LIG}^{1}$ & 1,30 & 6,11 & 7,82 & 1,22 & 3,2 \\
\hline $\mathrm{NDT}_{\text {est }}\left(T D N_{e s t}\right)^{1,3}$ & 70,26 & 65,78 & 60,19 & 75,43 & 62,88 \\
\hline
\end{tabular}

$1 \% \mathrm{MS} ; 2 \%$ do $\mathrm{N}$ total; ${ }^{3}$ estimado pelas equações do NRC (2001) para consumo de três vezes a manteça. FS = farelo de soja; FA38 = farelo de algodão com $38 \%$ de PB; FA28 = farelo de algodão com $28 \%$ de PB e FSU $=\mathrm{FS}+$ uréia $\left(1 \% D M ;{ }^{2} \%\right.$ total $\mathrm{N} ;{ }^{3}$ estimated by NRC (2001) assuming an intake of three times the maintenance. SBM = soybean meal; $C S M 38=$ cottonseed meal with $38 \% \mathrm{CP}$ CSM28 $=$ cottonseed meal with $28 \%$ CP and SBMU $=$ SBM plus urea).

Tabela 3 - Teores médios de MS, MO, PB, PDR, PNDR, NNP, NIDA, EE, FDN, FDNcp, CNF, LIG e NDT obtidos nas dietas experimentais

Table 3 - $\quad$ Average contents of DM, OM, CP, RDP, RUP, NPN, ADIN, EE, NDF, NDFap, NFC, lignin and TDN estimated for the four experimental diets

\begin{tabular}{|c|c|c|c|c|}
\hline \multirow[t]{2}{*}{$\begin{array}{l}\text { Item } \\
\text { Item }\end{array}$} & \multicolumn{4}{|c|}{$\begin{array}{c}\text { Dieta } \\
\text { Diet }\end{array}$} \\
\hline & $\begin{array}{c}\mathrm{FS} \\
S B M\end{array}$ & $\begin{array}{l}\text { FA38 } \\
\text { CSM } 38\end{array}$ & $\begin{array}{l}\text { FA28 } \\
\text { CSM } 28\end{array}$ & $\begin{array}{c}\text { FSU } \\
S B M U\end{array}$ \\
\hline MS (DM, \%) & 53,03 & 53,32 & 53,46 & 53,17 \\
\hline MO $(O M)^{1}$ & 94,23 & 93,91 & 93,98 & 94,69 \\
\hline $\mathrm{PB}(C P)^{1}$ & 14,71 & 15,37 & 14,65 & 14,62 \\
\hline $\operatorname{PDR}(R D P)^{1}$ & 10,01 & 10,49 & 10,80 & 11,45 \\
\hline $\operatorname{PNDR}(R U P)^{1}$ & 4,71 & 4,88 & 3,85 & 3,17 \\
\hline $\mathrm{NNP}(N P N)^{2}$ & 35,32 & 35,75 & 36,35 & 46,25 \\
\hline NIDA $(A D I N)^{2}$ & 1,66 & 1,54 & 1,70 & 1,64 \\
\hline $\mathrm{EE}^{1}$ & 2,26 & 2,45 & 1,91 & 2,45 \\
\hline $\mathrm{FDN}(N D F)^{1}$ & 44,02 & 49,39 & 52,90 & 43,87 \\
\hline FDNcp $(\text { NDFap })^{1}$ & 39,48 & 46,20 & 48,45 & 39,76 \\
\hline $\mathrm{CNF}(N F C)^{1}$ & 34,13 & 27,59 & 25,42 & 36,75 \\
\hline $\mathrm{LIG}^{1}$ & 2,44 & 4,36 & 5,05 & 2,41 \\
\hline $\mathrm{NDT}_{\text {est }}\left(T D N_{e s t}\right)^{1,3}$ & 65,83 & 64,04 & 61,80 & 67,90 \\
\hline
\end{tabular}

$1 \% \mathrm{MS} ;{ }^{2} \%$ do $\mathrm{N}$ total; ${ }^{3}$ estimado pelas equações do NRC (2001), para consumo de três vezes a manteça. $\mathrm{FS}=$ farelo de soja; $F A 38=$ farelo de algodão com $38 \%$ de PB; FA28 = farelo de algodão com $28 \%$ de PB e FSU = FS + uréia ( $1 \% D M ; 2 \%$ total $N \cdot{ }^{3}$ estimated by NRC (2001) assuming an intake of three times the maintenance. $S B M=$ soybean meal; CSM38 = cottonseed meal with $38 \%$ CP; CSM $28=$ cottonseed meal with $28 \% C P$ and SBMU = SBM plus urea).
O experimento foi constituído de quatro períodos de 18 dias, sendo os 11 primeiros destinados à adaptação dos animais às dietas e o restante à coleta de dados. Os animais foram alojados em baias individuais providas de cocho e bebedouro automático e receberam alimentação na forma de mistura completa, ad libitum, duas vezes ao dia, após as ordenhas da manhã e da tarde, de modo a permitir 5 a $10 \%$ de sobras em relação à matéria natural do alimento oferecido. O consumo diário foi medido pela diferença entre a quantidade fornecida e as sobras. No período de coleta, diariamente foram obtidas amostras do alimento fornecido e das sobras, que formaram uma amostra composta representativa por animal em cada período, as quais foram armazenadas em sacos plásticos e congeladas a $-20^{\circ} \mathrm{C}$ para análise posterior.

O peso dos animais foi registrado ao início e ao final de cada período experimental. As ordenhas foram realizadas duas vezes ao dia, às 6 e 16h, medindo-se diariamente as produções de leite diariamente para acompanhamento do desempenho dos animais. No 15 o dia do período de coleta, foram feitas amostras individuais em cada ordenha, que, posteriormente, formaram uma amostra composta, proporcional às produções dos períodos da manhã e da tarde, conforme recomendado por Broderick \& Clayton (1997). As amostras de leite foram analisadas quanto aos teores de gordura, segundo Pregnolato \& Pregnolato (1985), e nitrogênio total, conforme descrito por Silva \& Queiroz (2002). A PL foi corrigida para 3,5\% de gordura (PLC) por meio da equação citada por Sklan et al. (1992): $\mathrm{PLC}=(0,432+0,1625$ x G) $x \mathrm{~kg}$ de leite, em que $\mathrm{G}=\%$ de gordura no leite.

A determinação da digestibilidade aparente dos nutrientes foi realizada utilizando-se a FDNi como indicador interno, obtida após 144 horas de incubação in situ dos alimentos fornecidos, das sobras e das fezes em sacos Ankon ${ }^{\circledR}$ (filter bag F57), segundo Cochran et al. (1986). Foram coletadas duas amostras de fezes, uma a partir das $8 \mathrm{~h}$ no $12^{\circ}$ dia e a outra às $16 \mathrm{~h}$ do $16^{\circ}$ dia do período de coleta, conforme descrito por Ítavo et al. (2002).

Ao término do experimento, as amostras de alimentos, fezes e sobras foram descongeladas, pré-secas em estufa de ventilação forçada $\left(60 \pm 5^{\circ} \mathrm{C}-72\right.$ a 96 horas $)$ e, posteriormente, trituradas a $1 \mathrm{~mm}$ em moinho tipo Willey. As análises dos teores de MS, CIN, EE, FDN, FDA e CNT foram feitas segundo método descrito por Silva \& Queiroz (2002). A porcentagem de CNF nos concentrados foi obtida conforme relatado por Hall \& Akinyode (2000): $\mathrm{CNF}=100-((\%$ $\mathrm{PB}-\% \mathrm{PBU}+\% \mathrm{U})+\% \mathrm{FDN}+\% \mathrm{EE}+\%$ cinzas); e a de NDT: $\mathrm{NDT}=\mathrm{PBd}+\mathrm{FDNd}+\mathrm{CNFd}+2,25 \mathrm{xEEd}$, em que PBd, FDNd, CNFd e EEd representam o total de nutrientes digestíveis, 
conforme descrito por Weiss et al. (1992) e adotado pelo NRC(2001).

A eficiência alimentar foi computada para cada vaca, dividindo-se a produção média de leite pela ingestão média de MS de cada período experimental (Valadares Filho et al., 2000). Da mesma forma, procedeu-se ao cálculo da eficiência de utilização de nitrogênio, dividindo-se o N-total médio do leite pela ingestão média de N-total da dieta (Broderick, 2003).

As análises estatísticas foram feitas segundo o delineamento em quadrado latino, aplicando-se o teste de Dunnett a 5\% de probabilidade, comparando-se as dietas FA38, FA28 e FSU à dieta controle (FS) para todas as variáveis analisadas.

\section{Resultados e Discussão}

Os consumos médios diários de $\mathrm{MS}, \mathrm{MO}, \mathrm{PB}, \mathrm{PDR}$, PNDR, EE, FDN, CNF e NDT (em kg/dia), de MS e FDN (em $\% \mathrm{PV}$ ) e de MS (em g/ $\mathrm{kg}^{0,75}$ ), com os respectivos coeficientes de variação (CV), são apresentados na Tabela 4.

Não houve diferença significativa $(\mathrm{P}>0,05)$ entre as dietas para os consumos de MS expressos nas diferentes unidades e para os consumos de MO. Os consumos de MS obtidos com todas as dietas foram próximos aos verificados por Pereira et al. (2005 a, b) em vacas alimentadas com uma dieta contendo $15,5 \%$ de PB na MS $(19,11 \mathrm{~kg} / \mathrm{dia}, 3,42 \% \mathrm{PV}$ e $166,28 \mathrm{~g} / \mathrm{kg}^{0,75}$ ) no terço inicial da lactação.

Os valores obtidos em todos os tratamentos nesse experimento (18,57 a 19,56 kg/dia) foram próximos aos descritos pelo NRC (2001), que preconiza consumo de MS de 18,2 a $19,8 \mathrm{~kg} /$ dia para vacas com média de $550 \mathrm{~kg}$ PV, PLC de 25 a $30 \mathrm{~kg}$ de leite e com ganhos de aproximadamente $0,200 \mathrm{~kg} / \mathrm{dia}$.

Embora os valores numéricos de consumo de MS na dieta contendo nível mais elevado de uréia (FSU) tenham sido um pouco inferiores, não diferiram $(\mathrm{P}>0,05)$ da dieta controle (FS), o que está de acordo com Valadares Filho et al. (2000), que relataram que maiores consumos de MS em dietas com $43 \%$ de NNP foram obtidos com $37 \%$ de CNF. Os dados de consumo verificados para a dieta com elevado teor de uréia (FSU) confirmam os reportados por Colovos et al. (1967), Holter et al. (1968), Plummer et al. (1971), Broderick et al. (1993) e Santos et al. (1998), mas contrariam os relatados por Oliveira et al. (2001), Silva et al. (2001) e Melo et al. (2003), que observaram redução no consumo de MS com a inclusão de níveis elevados de uréia nas dietas.

$O$ consumo de $\mathrm{PB}$ foi maior $(\mathrm{P}<0,05)$ quando os animais receberam a dieta $\mathrm{FA} 38$, em comparação à dieta controle (FS), provavelmente em razão do maior teor desse nutriente na dieta FA38 (Tabela 3), pois não foram observadas dife-
Tabela 4 - Consumos médios diários de MS, MO, PB, PDR, PNDR, EE, FDN, CNF, NDT e variação no PV dos animais (g/ dia) alimentados com as diferentes fontes protéicas na dieta

Table 4 - $\quad$ Average daily intake of DM, OM, CP, RDP, RUP, EE, NDF, NFC, and TDN and body weight variation according to different protein sources in the diet

\begin{tabular}{|c|c|c|c|c|c|}
\hline \multirow[t]{2}{*}{ Item } & \multicolumn{4}{|c|}{$\begin{array}{l}\text { Dieta } \\
\text { Diet }\end{array}$} & \multirow[t]{2}{*}{ CV (\%) } \\
\hline & $\begin{array}{l}\text { FS } \\
S B M\end{array}$ & $\begin{array}{l}\text { FA38 } \\
\text { CSM38 }\end{array}$ & $\begin{array}{l}\text { FA28 } \\
\text { CSM28 }\end{array}$ & $\begin{array}{l}\text { FSU } \\
S B M U\end{array}$ & \\
\hline & \multicolumn{4}{|c|}{$\begin{array}{l}\text { Consumo }(\mathrm{kg} / \mathrm{dia}) \\
\text { Intake }(\mathrm{kg} / \text { day })\end{array}$} & \\
\hline $\operatorname{MS}(D M)$ & 18,96 & 19,38 & 19,56 & 18,57 & 5,10 \\
\hline $\mathrm{MO}(O M)$ & 18,00 & 18,20 & 18,21 & 17,43 & 5,05 \\
\hline $\mathrm{PB}(C P)$ & 3,06 & $3,23 *$ & 3,12 & 2,92 & 5,06 \\
\hline PDR (RDP) & 1,47 & 1,56 & $1,69 *$ & $1,73^{*}$ & 7,59 \\
\hline PNDR (RUP) & 1,59 & $1,67 *$ & $1,44^{*}$ & $1,20 *$ & 3,11 \\
\hline $\mathrm{EE}(E E)$ & 0,58 & $0,65^{*}$ & $0,52 *$ & $0,62 *$ & 3,10 \\
\hline FDN $(N D F)$ & 7,85 & $8,89 *$ & $9,90 *$ & 7,36 & 6,12 \\
\hline $\mathrm{CNF}(N F C)$ & 7,20 & $5,73 *$ & $5,30 *$ & 7,45 & 6,48 \\
\hline \multirow[t]{2}{*}{ NDT $(T D N)$} & 13,88 & $12,64 *$ & $12,33^{*}$ & $13,35 *$ & 2,57 \\
\hline & \multicolumn{4}{|c|}{$\begin{array}{c}\text { Consumo }(\% \mathrm{PV}) \\
\text { Intake }(\% B W)\end{array}$} & \\
\hline $\operatorname{MS}(D M)$ & 3,29 & 3,33 & 3,40 & 3,22 & 4,90 \\
\hline \multirow[t]{2}{*}{$\mathrm{FDN}(N D F)$} & 1,36 & $1,53^{*}$ & $1,72 *$ & 1,27 & 5,85 \\
\hline & \multicolumn{4}{|c|}{$\begin{array}{c}\text { Consumo }(\mathrm{g} / \mathrm{kg} 0,75) \\
\text { Intake }\left(\mathrm{g} / \mathrm{kg}^{0.75}\right)\end{array}$} & \\
\hline \multirow[t]{2}{*}{$\mathrm{MS}(D M)$} & 161,08 & 163,56 & 166,44 & 157,85 & 4,88 \\
\hline & \multicolumn{4}{|c|}{$\begin{array}{c}\text { Variação do } \mathrm{PV}(\mathrm{g} / \text { dia }) \\
B W \text { change }(\mathrm{g} / \text { day })\end{array}$} & \\
\hline 11 dias (11 days) & 591 & 514 & 257 & 477 & 152,69 \\
\hline
\end{tabular}

${ }^{1}$ Médias na linha seguidas por $\left({ }^{*}\right)$ diferem do tratamento controle (FS) pelo teste de Dunnett $(P<0,05) ; C V=$ coeficiente de variação. $F S=$ farelo de soja; FA38 = farelo de algodão com $38 \%$ de PB; FA28 = farelo de algodão com $28 \%$ de PB e FSU = FS + uréia (Mean in the same rows with (*) differ from the control diet $(S B M)$ by Dunnett test $(P<0.05), C V=$ coefficient of variation. $S B M=$ soybean meal; CSM $38=$ cottonseed meal with $38 \%$ CP; CSM $28=$ cottonseed meal with $28 \% C P$ and $S B M U=S B M$ plus urea).

renças $(\mathrm{P}>0,05)$ para o consumo de $\mathrm{PB}$ entre as dietas FA28 e FSU em relação à FS. Os consumos de $\mathrm{PB}$ obtidos com todas as dietas foram similares aos relatados por Pereira et al. (2005 b), de 3,01 kg/dia para vacas no terço inicial de lactação consumindo dieta com $15,5 \%$ de PB na MS total.

Nas dietas FA28 e FSU, os consumos de PDR foram maiores $(\mathrm{P}<0,05)$ e não diferiram $(\mathrm{P}>0,05)$ dos observados para a dieta FA38 em relação à $\mathrm{FS}$, estando de acordo com os teores de PDR (Tabela 3 ) dessas dietas. Os consumos de PNDR foram mais baixos $(\mathrm{P}<0,05)$ para as dietas com FA28 e FSU e mais altos $(\mathrm{P}<0,05)$ para a FA38.

Pereira et al. (2005 a, b), ao alimentarem vacas nos terços inicial e médio da lactação com dietas contendo farelo de soja, fubá de milho e silagem de milho, observaram consumos de PDR de 1,90 e de PNDR de 1,11 kg/dia. Neste trabalho, 
os consumos médios de PDR e PNDR com a dieta FS foram de 1,47 e $1,59 \mathrm{~kg} /$ dia, diferença que pode ser explicada pelo maior valor de degradabilidade efetiva do farelo de soja utilizado por Pereira et al. (2005 a, b) em relação ao deste trabalho $(63,70$ vs $56,81 \%)$.

Os consumos de PDR e PNDR sugeridos pelo NRC (2001) para vacas com peso médio de $550 \mathrm{~kg}$ e PLC de $25 \mathrm{~kg} /$ dia foram de 1,74 e 1,20 kg/dia, respectivamente. As dietas FSU $(1,73$ e 1,20$)$ e FA28 $(1,69$ e 1,44) foram as que promoveram consumos mais próximos dos recomendados por esse conselho, enquanto a FS $(1,47$ e 1,59$)$ e a FA38 $(1,56$ e $1,67)$ resultaram em consumos de PDR inferiores e de PNDR superiores aos sugeridos pelo NRC (2001).

As dietas FA38 e FSU resultaram em maiores $(\mathrm{P}<0,05)$ e a FA28 em menores $(\mathrm{P}<0,05)$ consumos de $\mathrm{EE}$, certamente em razão das diferenças nos teores desse nutriente entre essas dietas (Tabela 3 ) e da ausência de diferença $(\mathrm{P}>0,05)$ entre os consumos de MS.

Nas dietas FA38 e FA28, os consumos de CNF foram menores $(\mathrm{P}<0,05)$, possivelmente em virtude do menor teor desse componente nessas dietas (Tabela 3 ), e não diferiram $(\mathrm{P}>0,05)$ entre a dieta FSU e a FS. Os consumos de NDT foram menores $(\mathrm{P}<0,05)$ quando os animais foram alimentados com as dietas FA38, FA28 e FSU em relação à dieta controle (FS), o que pode estar relacionado ao menor teor deste nutriente nas dietas FA38 e FA28 (Tabela 3) e ao maior consumo numérico de MS, que não foi suficiente para compensar os menores teores de NDT dessas dietas.

Os consumos de FDN expressos em kg/dia e em \%PV foram maiores $(\mathrm{P}<0,05)$ quando os animais foram alimentados com dietas contendo farelo de algodão (FA38 e FA28), em relação à dieta controle (FS), sendo próximos ao preconizado por Mertens (1994) para otimizar a ingestão de MS $(1,2 \pm 0,1 \%$ do PV) e ao encontrado por Pereira et al. (2005 a, b). As diferenças encontradas entre as dietas são justificadas pelo maior conteúdo de FDN nas dietas à base de farelos de algodão. Os maiores valores de consumo de FDN observados nas dietas FA38 e FA28 estão de acordo com o proposto por Valadares Filho et al. (2000), que estimaram consumo máximo de FDN em dieta com $27 \%$ de CNF dietético.

Os valores de consumo de FDN estimados para as dietas FA38 e FA28 (1,53 e 1,72 \% PV) foram superiores ao preconizado por Mertens (1994). Segundo Allen (2000), reduções na ingestão de MS de vacas lactantes pela infusão de material inerte em até $25 \%$ do volume do retículorúmen foram observadas somente quando os animais estavam em balanço energético negativo. Neste trabalho, todas as vacas ganharam peso, o que pode explicar o maior consumo de FDN proporcionado pelas dietas FA38 e FA28. Embora essas dietas tenham proporcionado maior enchimento ruminal, a ingestão total de MS não foi significativamente diferente entre as dietas, apesar de ter sido numericamente inferior para o FS em relação às dietas contendo farelo de algodão. Detmann et al. (2003) analisaram um conjunto de dados obtidos em experimentos com bovinos confinados alimentados com forrageiras tropicais e identificaram, subjetivamente, que a fase de transição para os controles físicos e metabólicos se encontra entre os níveis dietéticos de FDN de 39 a 44\% da MS, de modo que, nesse intervalo, são mantidas comuns ambas as fases. Esses autores concluíram que a estimação do consumo de MS em bovinos consumindo forrageiras tropicais utilizando-se um modelo bifásico estático pode incorrer em erro, em virtude da inconsistência do consumo de FDN durante a fase atribuída ao controle físico do consumo e, possivelmente, pelo fato de a transição para a fase de controle metabólico ser representada por um intervalo e não especificamente por um ponto de inversão de mecanismos regulatórios. Esses autores também citaram, para bovinos, consumos de FDN (\%PV) superiores a 1,2 \% PV em aproximadamente $39 \%$ dos dados analisados, confirmando observações de Allen (2000), que afirmou que as diferenças observadas entre experimentos quanto ao declínio na IMS com o aumento do FDN dietético sugerem que o efeito de enchimento do FDN difere entre as dietas.

O consumo médio de FDN verificado neste estudo para a dieta FA28 foi semelhante ao descrito por Grings et al. (1991), que, em vacas em lactação alimentadas com dietas contendo níveis crescentes de proteína, obtidos pela inclusão de farelo de algodão em substituição à cevada e ao milho, observaram consumo médio de FDN de 1,63\% do PV. Mayer et al. (1997), avaliando diferentes fontes de PNDR, não encontraram diferenças no consumo de MS e FDN da dieta com farelo de algodão (1,57 e 1,54\% PV) em relação ao farelo de soja e ao grão de soja. Diferenças no consumo de MS entre tratamentos à base de farelo de algodão ou farelo de soja também não foram observadas por Barraza et al. (1991), Bernard (1997), Blackwelder et al.(1998), Imaizumi et al. (2002) e Mena et al. (2004).

$\mathrm{Na}$ Tabela 5 são descritos os coeficientes de digestibilidade aparente total de MS, MO, EE, PB, FDN, $\mathrm{CNF}$ e os teores de NDT de acordo com as dietas testadas.

Os coeficientes de digestibilidade da MS, MO e FDN obtidos com as dietas FA38, FA28 e FSU foram inferiores $(\mathrm{P}<0,05)$ aos observados com a dieta controle. Os valores de digestibilidade da MS condizem com os de degradabilidade efetiva relatados por Pina (2005) para a MS 
Tabela 5 - Coeficientes médios totais de digestibilidade aparente de MS (CDMS), MO (CDMO), PB (CDPB), EE (CDEE), FDN (CDFDN) e CNF (CDCNF) e teores de NDT obtidos para as dietas experimentais

Table 5 - Average apparent total tract digestibility coefficients of DM (DCDM), OM (DCOM), CP(DCCP), RDP(DCRDP), RUP(DCRUP), EE (DCEE), NDF(DCNDF), NFC (DCNFC) and TDN(TDN) contents of the four experimental diets

\begin{tabular}{|c|c|c|c|c|c|}
\hline \multirow[t]{2}{*}{ Item } & \multicolumn{4}{|c|}{$\begin{array}{l}\text { Dieta } \\
\text { Diet }\end{array}$} & \multirow[t]{2}{*}{ CV (\%) } \\
\hline & $\begin{array}{c}\mathrm{FS} \\
S B M\end{array}$ & $\begin{array}{l}\text { FA38 } \\
\text { CSM38 }\end{array}$ & $\begin{array}{l}\text { FA28 } \\
\text { CSM28 }\end{array}$ & $\begin{array}{l}\text { FSU } \\
S B M U\end{array}$ & \\
\hline $\begin{array}{l}\text { CDMS } \\
D C D M\end{array}$ & 68,19 & $61,81 *$ & $59,85^{*}$ & $66,45^{*}$ & 3,01 \\
\hline $\begin{array}{l}\text { CDMO } \\
\text { DCOM }\end{array}$ & 69,61 & $63,36^{*}$ & $61,04 *$ & $67,82 *$ & 2,73 \\
\hline $\begin{array}{l}\text { CDPB } \\
D C C P\end{array}$ & 72,57 & $66,18 *$ & $68,39 *$ & 71,54 & 4,04 \\
\hline $\begin{array}{l}\text { CDEE } \\
D C E E\end{array}$ & 82,65 & $87,14 *$ & $86,85 *$ & 81,81 & 2,37 \\
\hline $\begin{array}{l}\text { CDFDN } \\
D C N D F\end{array}$ & 50,87 & $44,97 *$ & $43,68 *$ & $47,43^{*}$ & 5,98 \\
\hline $\begin{array}{l}\text { CDCNF } \\
D C N F C\end{array}$ & 90,61 & 89,76 & 91,36 & 89,21 * & 2,14 \\
\hline $\begin{array}{l}\text { NDT }(\% \mathrm{MS}) \\
T D N \% D M\end{array}$ & 72,54 & $64,63^{*}$ & $63,05^{*}$ & 72,48 & 2,53 \\
\hline
\end{tabular}

${ }^{1}$ Médias na linha seguidas por $\left({ }^{*}\right)$ diferem do tratamento controle (FS) pelo teste de Dunnett $(P<0,05) ; C V$ = coeficiente de variação. $F A 38=$ farelo de algodão com $38 \%$ de PB; FA28 = farelo de algodão com $28 \%$ de PB e FSU $=$ FS mais uréia (Means in the same rows with $\left(^{*}\right)$ differ from the control diet (SBM) by Dunnett test $(P<0.05), C V=$ coefficient of variation. $S B M=$ soybean meal; CSM38 = cottonseed meal with $38 \%$ CP; CSM28 = cottonseed meal with $28 \%$ CP and $S B M U=S B M$ plus urea)

do fubá de milho e dos farelos de soja e de algodão com 28 e $38 \%$ de $\mathrm{PB}(53,75 ; 63,93 ; 41,03$ e $46,85 \%$, respectivamente). Os coeficientes de digestibilidade do EE e da PB foram menores $(\mathrm{P}<0,05)$ para todas as dietas à base de farelo de algodão, enquanto o de digestibilidade dos CNF foi inferior $(\mathrm{P}<0,05)$ para a dieta FSU. A menor digestibilidade dos CNF na dieta FSU pode ser explicada pela maior proporção $(36,75 \%)$ desse componente nessa dieta. Para a dieta rica em uréia (FSU), a menor digestibilidade da FDN provavelmente se deve à maior proporção de milho $(62,01 \% \mathrm{MS})$ nessa dieta, com observado por Valadares Filho et al. (2000) e Detmann et al. (2003), que observaram redução na digestibilidade da FDN com aumento do CNF dietético. A menor digestibilidade da FDN para as dietas FA38 e FA28 possivelmente decorreu do maior consumo desse nutriente em relação à dieta FS (Tabela 4) e dos maiores teores de lignina nas dietas FA38 e FA28 (Tabelas 2 e 3), os quais, segundo Van Soest, (1994) estão relacionados à digestibilidade.

O menor coeficiente de digestibilidade observado para PB na dieta contendo FA38 provavelmente se deve ao maior consumo desse nutriente para essa dieta (Tabela 4). Para a dieta FA28, esse fato pode estar associado ao maior consumo numérico de MS, correlacionado positivamente à taxa de passagem e inversamente à digestibilidade. Os elevados coeficientes de digestibilidade para o EE nas dietas FA28 e FA38 (87,14 e 86,85\%), respectivamente, podem ser resultantes da menor concentração deste nutriente nessas dietas. Mayer et al. (1997) também citaram valores bem próximos aos deste estudo para essas variáveis.

As médias diárias para a produção e composição do leite, da eficiência de utilização da MS e nitrogênio ingerido, com os respectivos coeficientes de variação, são apresentadas na Tabela 6.

Não houve diferença $(\mathrm{P}>0,05)$ para PL, PLC, G $(\%)$ e G (g/dia). A ausência de significância para a PL pode ser explicada pela ausência de resposta no consumo de MS. Entretanto, houve redução numérica de $1,16 \mathrm{~kg}$ de leite para os animais submetidos à dieta contendo FA28 em relação à dieta controle (FS), provavelmente em razão do menor consumo de NDT na dieta com FA28 (Tabela 4). A ausência de diferença $(\mathrm{P}>0,05)$ para a PLC está de acordo com a ausência de significância $(\mathrm{P}>0,05)$ para os teores $(\mathrm{G} \%)$ e a produção diária de gordura (g/dia) no leite. Resultados semelhantes foram relatados por Bernard (1997), Mayer et al. (1997), Blackwelder et al. (1998) e Mena et al. (2001; 2004). Contudo, são contrários aos relatados por Imaizumi et al. (2002), que observaram aumento linear significativo para o teor e a produção diária de gordura no leite com a inclusão de farelo de algodão, semelhantemente ao descrito por Grings et al. (1991).

Os resultados para PL e PLC obtidos neste trabalho estão de acordo com os de Blackwelder et al. (1998), que verificaram a capacidade do farelo de algodão em manter PL e PLC comparáveis ao farelo de soja com a adição ou não de fontes de PNDR em dietas com 17\% PB na MS total. Corroboram também os descritos por Van Horn et al. (1979), que compararam o farelo de algodão aos de amendoim e de soja em dietas com $16,4 \%$ de PB na MS total e não observaram reduções na PL para animais alimentados com farelo de algodão em relação aos demais. Também Bernard (1997) concluiu que o farelo de algodão foi similar ao de soja quando a dieta continha soro de leite. Produções de leite semelhantes entre dietas contendo farelo de soja e de algodão foram relatadas também por Mayer et al. (1997) e Mena et al. $(2001,2004)$.

A eficiência de utilização da MS foi diferente $(\mathrm{P}<0,05)$ com a dieta FA28, o que pode ser explicado pela associação numérica do maior consumo MS (Tabela 4) e pela menor PL observadas para essa dieta. Resultados semelhantes foram verificados também por Imaizumi et al. (2002). Os resultados obtidos neste experimento para eficiência de utilização de MS encontram-se no intervalo médio $(1,38$ e 1,16$)$ descrito 
Tabela 6 - Médias diárias para PL, PLC, produção de gordura (G) no leite (em \% e em g/dia) e eficiência de utilização do nitrogênio ( $\mathrm{kg} \mathrm{N}$ no leite/kg Ningerido) e da MS ingerida ( $\mathrm{kg}$ de leite/kg MS ingerida) obtidas para as diferentes fontes protéicas das dietas

Table 6 - $\quad$ Average daily milk yield (MY), 3.5\% fat corrected milk (FCM), contents and yields of milk fat and protein and feed ( $\mathrm{kg}$ of milk/ $\mathrm{kg}$ dry matter intake) and nitrogen ( $\mathrm{kg}$ of $\mathrm{N}$ in the milk / $\mathrm{kg} \mathrm{N}$ intake) efficiencies of diets with supplemented with different protein sources

\begin{tabular}{|c|c|c|c|c|c|}
\hline \multirow[t]{2}{*}{ Item } & \multicolumn{4}{|c|}{$\begin{array}{l}\text { Dieta } \\
\text { Diet }\end{array}$} & \multirow[t]{2}{*}{$\mathrm{CV}(\%)$} \\
\hline & $\begin{array}{c}\mathrm{FS} \\
S B M\end{array}$ & $\begin{array}{l}\text { FA38 } \\
\text { CSM } 38\end{array}$ & $\begin{array}{l}\text { FA28 } \\
\text { CSM } 28\end{array}$ & $\begin{array}{l}\text { FSU } \\
S B M U\end{array}$ & \\
\hline $\begin{array}{l}\mathrm{PL}(\mathrm{kg} / \mathrm{d}) \\
M Y(\mathrm{~kg} / \text { day })\end{array}$ & 23,85 & 23,76 & 22,69 & 23,42 & 5,23 \\
\hline $\begin{array}{l}\text { PLC }(\mathrm{kg} / \mathrm{d}) \\
F C M\end{array}$ & 25,11 & 23,67 & 24,75 & 24,13 & 6,43 \\
\hline $\begin{array}{l}\text { Eficiência MS } \\
\text { Feed efficiency }\end{array}$ & S 1,25 & 1,22 & $1,16^{*}$ & 1,29 & 5,29 \\
\hline $\begin{array}{l}\text { Eficiência } \mathrm{N} \\
N \text { efficiency }\end{array}$ & 0,248 & 0,217 * & $0,224 *$ & 0,252 & 5,35 \\
\hline $\begin{array}{l}\mathrm{G}(\%) \\
F(\%)\end{array}$ & 3,85 & 3,53 & 4,07 & 3,73 & 5,30 \\
\hline $\begin{array}{l}\mathrm{G}(\mathrm{g} / \mathrm{dia}) \\
F(\mathrm{~g} / \text { day })\end{array}$ & 911,50 & 825,01 & 919,79 & 862,50 & 9,63 \\
\hline $\begin{array}{l}\mathrm{PB}(\%) \\
C P(\%)\end{array}$ & 3,19 & $2,98^{*}$ & 3,12 & 3,17 & 5,07 \\
\hline $\begin{array}{l}\text { PB (g/dia) } \\
C P \text { (g/day) }\end{array}$ & 756,92 & $702,36 *$ & $701,13 *$ & 732,25 & 6,14 \\
\hline
\end{tabular}

${ }^{1}$ Médias na linha seguidas por ${ }^{*}$ ) diferem do tratamento controle (FS) pelo teste de Dunnett $(P<0,05) ; C V=$ coeficiente de variação. $F A 38=$ farelo de algodão com $38 \%$ de PB; FA28 = farelo de algodão com $28 \%$ de PB e FSU $=$ FS mais uréia (Mean in the same rows with (*) differ from the control diet (SBM) by Dunnett test $(P<0.05), C V=$ coefficient of variation. $S B M=$ soybean meal; $C S M 38=$ cottonseed meal with $38 \%$ CP; CSM28 = cottonseed meal with $28 \% C P$ and SBMU $=S B M$ plus urea).

por Pereira et al. (2005 a, b) para vacas nos terços inicial e médio da lactação, respectivamente. A eficiência de utilização de nitrogênio também foi menor $(\mathrm{P}<0,05)$ para as dietas à base de farelo de algodão e pode ser explicada pela menor $(\mathrm{P}<0,05)$ produção diária de proteína no leite $(\mathrm{PB}$ g/dia $)$ com ambas as dietas e pelo menor $(\mathrm{P}<0,05)$ teor de proteína do leite (PB\%) com a dieta FA38.

Provavelmente essa redução no teor de PB do leite das vacas alimentadas com a dieta FA38 seja explicada pela ausência de farelo de soja nessa dieta, pois, segundo Schwab, citado por Santos et al. (1998), a síntese de proteína do leite é sensível ao perfil de aminoácidos na digesta duodenal e o perfil de aminoácidos do farelo de soja é inferior somente ao da proteína microbiana e ao da proteína da farinha de peixe. Assim, a redução no teor de PB do leite pode ser decorrente do menor valor biológico da proteína do farelo de algodão em relação ao de soja.

Segundo Blackwelder et al. (1998), o farelo de algodão possui menor concentração de lisina e metionina em relação ao de soja. Esses autores encontraram diferença significativa na concentração plasmática de lisina $(57,9$ e 50,2 ì mol), mas não na de metionina (17,7 e 17,1 ì mol) em vacas alimentadas com farelos de soja e algodão, respectivamente. Entretanto, não encontraram diferença significativa no teor protéico do leite $(3,14$ e 3,18\%), confirmando a sugestão de Coopock et al. (1987) de que a diferença entre os farelos de soja e de algodão poderia ser atribuída aos teores de lisina.

Os limites de conversão do nitrogênio alimentar para nitrogênio no leite não são claramente definidos. Na tentativa para estabelecer essa eficiência de conversão, foram avaliados 334 tratamentos, provenientes de 62 pesquisas, sendo determinado valor médio de 0,270 . São diversos os fatores que afetam a eficiência de utilização de N. Entre eles, destacam-se o cruzamento, a ordem de lactação, o estágio de lactação, o conteúdo de proteína do leite, a fonte de carboidratos e a quantidade e qualidade da proteína dietética (Chase, 2003).

Os resultados obtidos nesse experimento para eficiência de utilização de nitrogênio foram próximo aos de 0,253 e 0,274 relatados por Pereira et al. (2005 a, b) para vacas alimentadas com dietas à base de farelo de soja, fubá de milho e silagem de milho nos terços inicial e médio da lactação, respectivamente. Imaizumi et al. (2002) também verificaram valores de eficiência $(0,27 ; 0,25$ e 0,25$)$ semelhantes aos obtidos nesse trabalho para os tratamentos com $100 \%$ farelo de soja e aqueles em que o farelo de algodão substituiu 50 e 100\% do farelo de soja, respectivamente.

A utilização de uréia em até $5 \%$ da MS do concentrado na dieta FSU permitiu vislumbrar a possibilidade de maior inclusão de nitrogênio não-protéico proveniente desta fonte em dietas para vacas lactantes (atualmente, recomenda-se $1 \%$ na MS da dieta total). Não foi encontrada nesse trabalho diferença significativa para produção e composição do leite e eficiência de utilização da matéria seca e do nitrogênio para síntese de leite para a dieta com elevado teor de uréia em relação à dieta controle, contendo FS (Tabela 6).

\section{Conclusões}

A utilização de $40 \%$ de concentrado com $5 \%$ de uréia/ sulfato de amônia na MS na dieta de vacas produzindo $25 \mathrm{~kg}$ de leite por dia não influenciou os parâmetros digestivos nem a produção e composição do leite. $\mathrm{O}$ farelo de algodão com $38 \%$ de $\mathrm{PB}$ pode substituir integralmente o farelo de soja quando utilizada silagem de milho como volumoso na proporção de $60 \%$ da MS da dieta total. 


\section{Literatura Citada}

ALLEN, M.S. Effects of diet on short-term regulation of feed intake by lactating dairy cattle. Journal of Dairy Science, v.83, p.1598-1624, 2000.

ALLEN, M.S. Physical constraints on voluntary intake of forages by ruminants. Journal of Animal Science, v.74, p.30633075, 1996.

BARRAZA, M.L.; COPPOCK C.E; BROOKS, K.N. Iron sulfate and feed pelleting to detoxify free gossypol in cottonseed diets for dairy cattle. Journal of Dairy Science, v.74, p.3457-3467, 1991.

BERNARD, J.K. Milk production and composition responses to source of protein supplement in diets containing wheat middlings. Journal of Dairy Science, v.80, p.938-942, 1997.

BLACKWELDER J.T.; HOPKINS, B.A.; DIAZ, D.E. et al. Milk production and plasma gossypol of cows fed cottonseed and oilseed meals with or without rumen-undegradable protein. Journal of Dairy Science, v.81, n.11, p.2934-2941, 1998.

BRODERICK, G.A; CRAIG, W.M.; RICKER, D.B. Urea versus true protein as supplement for lactating dairy cows fed grain plus mixtures of alfalfa and corn silages. Journal of Dairy Science, v.76, p.2266-2274, 1993.

BRODERICK, G.A. Effects of varying dietary protein and energy levelson the A production of lactating dairy cows. Journal of Dairy Science, v.86, p.1370-1381, 2003.

BRODERICK, G.A.; CLAYTON, M.K. A statistical evaluation of animal and nutritional factors influencing concentrations of milk urea nitrogen. Journal of Dairy Science, v.80, p.29642971, 1997.

CHASE, L.E. Nitrogen utilization in dairy cows - what are the limits of efficiency? In: CORNELL PROCEEDINGS CONFERENCE, 1., 2003, Ithaca. Proceedings... Ithaca: Cornell University, 2003. p.233-244

COCHRAN, R.C.; ADANS, D.C.; WALLACE, J.D. et al. Predicting digestibility of different diets with internal markers: evaluation of four potential markers. Journal of Dairy Science, v.63, p.1476-1483, 1986.

COLOVOS, N.F.; HOLTER, J.B.; DAVIS, H.A. et al. Urea for lactating dairy cattle. II Effect of various levels of concentrate urea on nutritive value of the ration. Journal of Dairy Science, v.50, n.4, p.523-526, 1967.

COOPOCK,C.E.; LANHAM, J.K.; HORNER, J.L. A review of the nutritive value and utilization of whole cottonseed, cottonseed meal and associated by-products by dairy cattle. Animal Feed Science and Technology, v.18, p.89-129, 1987.

DETMANN, E.; QUEIROZ, A.C.; CECON, P.R. et al. Consumo de fibra em detergente neutro por bovinos em confinamento. Revista Brasileira de Zootecnia, v.32, n.6, p.1763-1777, 2003 (supl.1).

FERREIRA, A.H. Eficiência de sistemas de produção de leite: uma aplicação da Análise envoltória de dados na tomada de decisão. Viçosa, MG: Universidade Federal de Viçosa, 2002. 120p. Dissertação (Mestrado em Economia Rural) - Universidade Federal de Viçosa, 2002.

GRINGS, E.E.; ROFFLER, R.E.; DEITELHOFF, D P. Response of dairy cows in early lactation to additions of cottonseed meal in alfafa-based diets. Journal of Dairy Science, v.74, p. 2580-2587, 1991 .

HALL, M.B.; AKINYODE, A. Cottonseed hulls: working with a novel fiber source. In: ANNUAL FLORIDA RUMINANT NUTRITION SYMPOSIUM, 11., 2000, Gainesville. Proceedings... Gainesville: 2000. p.179-186.

HOLTER, J.B.; COLOVOS, N.F.; DAWIS H.A. Urea for lactating dairy cattle. Journal of Dairy Science, v.51, p.1243-1248, 1968.

IMAIZUMI, H.; SANTOS, F.A.P.; VOLTOLINI, T.V. et al. Utilização de farelo de algodão como substituto do farelo de soja em dietas para vacas holandesas em lactação. In: REUNIÃO ANUAL DA SOCIEDADE BRASILEIRA DE ZOOTECNIA, 39.,
2002, Recife. Anais... Recife: Sociedade Brasileira de Zootecnia, 2002. (CD-ROM)

ÍTAVO, L.C.V.; VALADARES FILHO, S.C.; SILVA, F.F. et al. Comparação de indicadores e metodologia de coleta para estimativas de produção fecal e fluxo de digesta em bovinos Revista Brasileira de Zootecnia, v.31, n.4, p.1833-1839, 2002.

MAYER, L.R.R.; COELHO DA SILVA, J.F.; VALADARES FILHO, S.C et al. Rações com diferentes teores de proteína degradada no rúmen para vacas em lactação. 1. Consumo, produção e composição do leite. Revista Brasileira de Zootecnia, v.26, n.4, p.813-823, 1997.

MELO, A.A.S.; FERREIRA, M.A.; VERÁS, A.S.C et al. Substituição parcial do farelo de soja por uréia e palma forrageira (Opuntia fícus indica Mill) em dietas para vacas em lactação. I. Desempenho. Revista Brasileira de Zootecnia, v.32, n.3, p.727-736, 2003.

MENA, H.; SANTOS, J.E.P.; HUBER, J.T. et al. The effects of feeding varying amounts of gossypol from whole cottonseed and cottonseed meal in lactating dairy cows. Journal of Dairy Science, v.84, n.10, p.2231-2239, 2001.

MENA, H.; SANTOS, J.E.P.; HUBER, J.T. et al. The effects of varying gossypol intake from whole cottonseed and cottonseed meal on lactation and blood parameters in lactating dairy cows. Journal of Dairy Science, v.87, n.8, p.2506-2518, 2004.

MERTENS, D.R. Regulation of forage intake. In: FAHEY JR., G.C.; COLLINS, M.; MERTENS, D.R. et al. (Eds.) Forage quality, evaluation, and utilization. Madison: American Society of Agronomy, Crop Science Society of American and Soil Science Society of America, 1994. p.450-493.

NATIONAL RESEARCH COUNCIL - NRC. Nutrient requirements of dairy cattle. 7.ed. Whashington, D.C.: National Academic Press, 2001. 381p.

OLIVEIRA, A.S.; VALADARES, R.F.D.; VALADARES FILHO, S.C. et al. Consumo, digestibilidade aparente, produção e composição do leite em vacas alimentadas com quatro níveis de compostos nitrogenados não protéicos. Revista Brasileira de Zootecnia v.30, n.4, p.1358-1366, 2001

PEREIRA, M.L.A.; VALADARES FILHO, S.C.; VALADARES, R.F.D. et al. Consumo, digestibilidade aparente total, produção e composição do leite em vacas no terço médio da lactação alimentadas com níveis crescentes de proteína bruta no concentrado. Revista Brasileira de Zootecnia, v. 34, n.3, p.1040-1050, 2005a.

PEREIRA, M.L.A.; VALADARES FILHO, S.C.; VALADARES, R.F.D. et al. Consumo, digestibilidade aparente total, produção e composição do leite em vacas no terço inicial da lactação alimentadas com níveis crescentes de proteína bruta no concentrado. Revista Brasileira de Zootecnia, v. 34, n.3, p.1029-1039, 2005b.

PINA, D.S. Fontes de proteína para vacas em lactaça Viçosa, MG: Universidade Federal de Viçosa, 2003. 61p. Dissertação (Mestrado em Zootecnia) - Universidade Federal de Viçosa, 2005

PREGNOLATTO, W.; PREGNOLATTO, N.P. Normas analíticas do instituto Adolfo Lutz - métodos químicos e físicos para análise de alimentos. 3.ed. São Paulo, 1985. v.1, p.533.

PLUMMER, J.R.; MILES, J.T.; MONTGOMERY, M.J. Effect of urea in the concentrate mixture on intake and production of cows fed corn silage as the only forage. Journal of Dairy Science, v.54, n.12, p.1861-1865, 1971

SANTOS, F.A.P.; SANTOS, J.E.P.; THEURER, C.B. et al. Effects of rumen-undegradable protein on dairy cow performance: a 12 year literature review. Journal of Dairy Science, v.81, p.3182-3213, 1998

SILVA, J.D.; QUEIROZ, A.C. Análise de alimentos (Métodos químicos e biológicos). 3.ed. Viçosa, MG: Universidade Federal de Viçosa, 2002. 235p.

SILVA, R.M.N.; VALADARES, R.F.D.; VALADARES FILHO, S.C. et al. Uréia para vacas em lactação. 1. Consumo, digestibilidade, 
produção e composição do leite. Revista Brasileira de Zootecnia, v.30, n.5, p.1639-1649, 2001.

SKLAN, D.; ASHKENAZI, R.; BRAUN, A. et al. Fatty acids, calcium soaps of fatty acids, and cottonseeds fed to high yielding cows. Journal of Dairy Science, v.75, p.2463-2472, 1992.

Van HORN, H.H.; ZOMETA, C.A.; WILCOX, C.J. et al. Complete rations for dairy cattle. VIII. Effect of percent and source of protein on milk yield and ration digestibility. Journal of Dairy Science, v.62, p.1086-1093, 1979.

Van SOEST, P.J. Nutritional ecology of the ruminant. 2.ed. London: Constock Publishing Associates, 1994. 476p.
VALADARES FILHO, S.C.; BRODERICK, G.A.; VALADARES, R.F.D. et al. Effect of replacing alfalfa silage with high moisture corn on nutrient utilization and milk production. Journal of Dairy Science, v. 83, p.106-114, 2000.

WEISS, W.P.; CONRAD, H.R.; St. PIERRE, N.R. A theoreticallybased model for predicting total digestible nutrient values of forages and concentrates. Animal Feed Science and Technology, v.39, p.95-110, 1992.

Recebido: 03/08/05 Aprovado: 30/01/06 